\title{
Using a Syndromic Approach to Study Health Impact and Risk Factors of Alcohol Intoxication in Reunion Island
}

\author{
Pascal Vilain ${ }^{\star 1}$, Sophie Larrieu ${ }^{1}$, Xavier Combes², Arnaud Bourdé2, Pierre-Jean Marianne \\ dit Cassou ${ }^{3}$, Katia Mougin Damour ${ }^{4}$, Yves Jacques-Antoine ${ }^{5}$ and Laurent Filleul ${ }^{1}$
}

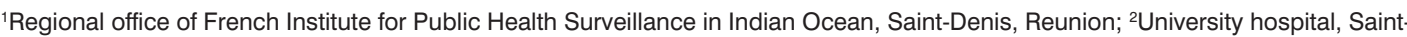
Denis, Reunion; ${ }^{3}$ University hospital, Saint-Pierre, Reunion; ${ }^{4}$ Hospital center, Saint-Paul, Reunion; ${ }^{5}$ Hospital center, Saint-Benoit, Reunion

\section{Objective}

Describe the emergency departments' visits for alcohol intoxication (AI) in Reunion Island and factors associated with their variations.

\section{Introduction}

In Reunion Island, alcohol is the most experienced psychoactive substance [1]. Alcohol consumption is characterized by a massive ingestion of hard liquor and an early experimentation. Health consequences are significant: a high annual incidence of fetal alcohol syndromes [2] and a higher premature mortality than in France mainland [1]. Reunion island is one the French regions most affected by addictive behaviors related to alcohol. However, existing data are insufficient concerning the current health impact and associated factors.

\section{Methods}

In Reunion Island, syndromic surveillance system is based on OSCOUR ${ }^{\circ}$ network (Organisation de la surveillance coordonnée des urgences) that collects data from all emergency departments of the island. Based on these data, a daily indicator of visits for "alcohol intoxication" syndrome was built by selecting CIM-10 codes F100 to F102, T51, X65, Y15 in principal or associated diagnosis between 2010 and 2012. Health impact of AI was first described comparing this indicator to all causes ED visits. Then, daily number of visits for AI was analyzed with time-series methods using generalized additive Poisson regression models allowing for overdispersion. The following variables were included in the model: long-term trend, seasonality, day of the week, public and school holidays, festivals and minimum social benefits.

\section{Results}

During the study period, the annual mean number of AI visits was 5600 , i.e. on average 15 visits per day (Figure 1). AI was the second leading cause of all visits after trauma. The AI mainly concerned men $(87 \%)$ and the age group of $24-54$ years. There was a significant increase in ED visits for AI during days of minimum social benefits payment (5 to 9 of each month) $(\mathrm{RR}=1,5[1,46-1,60])$, during weekends and publics holidays (Table 1).

\section{Conclusions}

This study demonstrated the interest of syndromic surveillance to monitor non-infectious diseases. Time-series models showed a robust association between ED visits and several factors. These results will be transmitted to health authorities in order to orient the public health policies.
Table 1. Risk factors associated to ED visits for alcohol intoxication in Réunion Island, 2010-2012

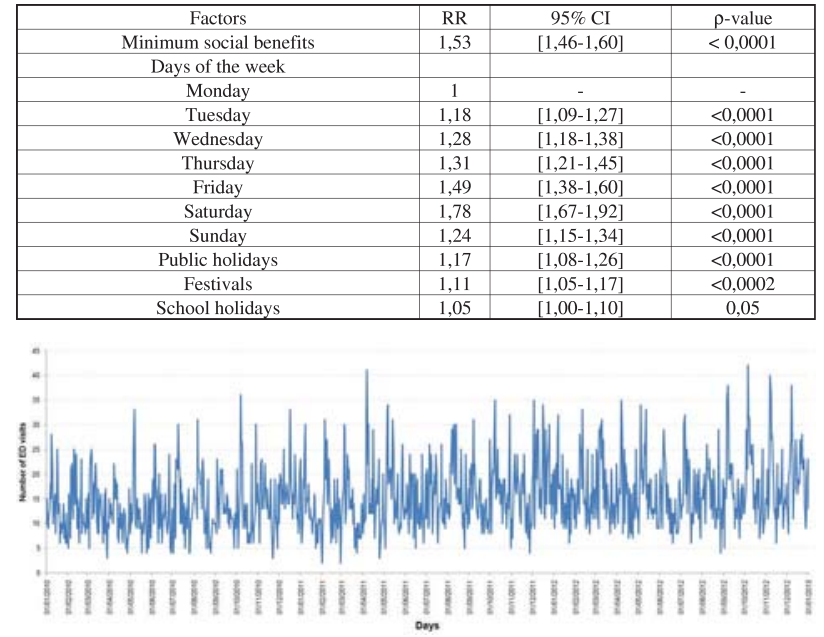

Figure 1. Daily number of ED visits for alcohol intoxication in Réunion Island, 2010-2012

\section{Keywords}

Alcohol intoxication; Syndromic surveillance; Reunion Island

\section{Acknowledgments}

We are thankful to Dr Angelini Tibert Marie France and all the practitioners of emergency departments.

\section{References}

[1] Observatoire Régional de la Santé de la Réunion. Tableau de bord sur les addictions à la Réunion [Internet]. Saint-Denis: ORS Réunion; 2012 Dec. 12p. Available from : http://www.ors-reunion.org/IMG/ file/tableaux_bord/TB_addictions_2012.pdf

[2] Observatoire Régional de la Santé de la Réunion. Exposition prénatale à l'alcool à la Réunion [Internet]. Saint-Denis: ORS Réunion; 2008 Sep. 3p. Available from : http://www.ors-reunion.org/IMG/file/tableaux_bord/expo_prenatale_alcool_2008.pdf

\section{*Pascal Vilain}

E-mail: pascal.vilain@ars.sante.fr 